\title{
Body-part-specific Representations of Semantic Noun Categories
}

\author{
Francesca Carota ${ }^{1}$, Rachel Moseley ${ }^{1}$, and Friedemann Pulvermüller ${ }^{1,2}$
}

\begin{abstract}
Word meaning processing in the brain involves ventrolateral temporal cortex, but a semantic contribution of the dorsal stream, especially frontocentral sensorimotor areas, has been controversial. We here examine brain activation during passive reading of object-related nouns from different semantic categories, notably animal, food, and tool words, matched for a range of psycholinguistic features. Results show ventral stream activation in temporal cortex along with category-specific activation patterns in both ventral and dorsal streams, including sensorimotor systems and adjacent pFC. Precentral activation reflected action-related semantic features of the word categories. Cortical regions implicated in mouth and face move-
\end{abstract}

\section{INTRODUCTION}

Language is the most essential tool to communicate about the external world. The ability to use concrete nouns to speak about objects is an early and necessary step in acquiring language (Tomasello, 2005). Referential meaning, the essential relationship between words and the objects they are used to speak about (Frege, 1980; Lyons, 1977; de Saussure, 1916), relies on perceptual experience of individual objects, which is generalized into categories by means of object representations and concepts (Tomasello, 2005). Objects of the same type and, with gradually more abstract word meaning, more variable types, are grouped under the same term, thus allowing the child to derive conceptual representations from the sensory input (Barsalou, 1999, 2008; Tomasello, 2005; Pulvermüller, 1999).

Object knowledge, however, does not necessarily subtend semantics, as the existence of meaningful words that do not refer to objects (e.g., write, however) documents. Indeed, even the meaning of object words has been claimed to be, to a degree, independent of visual knowledge about objects. For example, blind children do not seem to have difficulty in categorizing objects and learning words referring to them (e.g., Landau \& Gleitman, 1985), and similar semantic activations emerge

\footnotetext{
${ }^{1}$ Medical Research Council Cognition and Brain Sciences Unit, Cambridge, United Kingdom, ${ }^{2}$ Brain-Language Laboratory, Free University of Berlin
}

ments were sparked by food words, and hand area activation was seen for tool words, consistent with the actions implicated by the objects the words are used to speak about. Furthermore, tool words specifically activated the right cerebellum, and food words activated the left orbito-frontal and fusiform areas. We discuss our results in the context of category-specific semantic deficits in the processing of words and concepts, along with previous neuroimaging research, and conclude that specific dorsal and ventral areas in frontocentral and temporal cortex index visual and affective-emotional semantic attributes of object-related nouns and action-related affordances of their referent objects. in the brains of blind people and participants with normal vision (Mahon, Anzellotti, Schwarzbach, Zampini, \& Caramazza, 2009). One may therefore ask whether brain circuits for object processing are key to the semantic system of the human brain.

As visual modality and perceptual information, generally, are not a conditio sine qua non for semantic processing, an alternative approach to semantics has addressed the role of action context and social interactions in word meaning (Greenfield, 1991; Wittgenstein, 1953). Action contexts provide crucial information in semantic learning (Gleitman, 1994; Tomasello \& Kruger, 1992) and can explain aspects of the brain mechanisms for language (Pulvermüller \& Fadiga, 2010). A particular example comes from a range of neuroimaging studies reporting specific activation of the motor and premotor cortex during the comprehension of action-related words and sentences (Kemmerer \& Gonzalez-Castillo, 2008; Pulvermüller, 2005; Rizzolatti \& Craighero, 2004). For example, words typically used to speak about actions involving the mouth and face (e.g., speak) activated the inferior frontal precentral regions controlling face-mouth movements, whereas words related to actions involving the hands and arms (e.g., write) engaged dorsolateral precentral cortex, consistent with motor representation of hand-arm movements. This motor system activation in the dorsal stream specific to semantic categories appears over and above any general language-induced motor system activation related to phonological and lexical processing (D'Ausilio 
et al., 2009; Fazio et al., 2009; Pulvermüller et al., 2006; Pulvermüller, Shtyrov, \& Ilmoniemi, 2003; Fadiga, Craighero, Buccino, \& Rizzolatti, 2002). As semantically related motor systems activation could so far be demonstrated for words and sentences used to speak about actions (Pulvermüller \& Fadiga, 2010), one might claim that such dorsal stream involvement might be restricted to verbs and parts of speech with an overt referential relationship to actions, but not or less so to other word types. In contrast, if action knowledge is at the heart of language understanding, it might well be that the motor system of the human brain also becomes active specifically in the processing of words with more indirect semantic implications of action knowledge. Many nouns relate to objects, some of which are typically used for specific types of actions. In this sense, tools afford actions typically involving hand movements, and also tool words are therefore tied to action knowledge about such manual activity (hand-arm relationship), whereas food words imply the possibility of eating the referent object, as foods afford eating (thus implying face-mouth affordance, with possible additional hand-arm relationship). Might it be possible to document brain correlates of these differential but indirect semantic action links of nouns, possibly in the patterns of motor systems activation these semantic word categories elicit?

Previous studies have compared the processing of tool words to animal words and found premotor activation to the former word category in naming tasks (e.g., Chao, Weisberg, \& Martin, 2002; Chao, Haxby, \& Martin, 1999; Martin, Wiggs, Ungerleider, \& Haxby, 1996). However, it is not clear whether the activations seen in these experiments are related to the processing of word meaning or rather to that of the to-be-named stimulus pictures per se. It is well known that seeing, imagining, or thinking of both actions and tools sparks activity in the premotor cortex, especially precentral mirror and canonical sensorimotor neuron circuits (Grezes, Armony, Rowe, \& Passingham, 2003; Grezes \& Decety, 2002; Buccino et al., 2001; Hari et al., 1998; Grafton, Fadiga, Arbib, \& Rizzolatti, 1997; Rizzolatti, Fadiga, Gallese, \& Fogassi, 1996). Incidentally, whereas premotor activity was seen during naming of tool pictures, lateral precentral activation was not consistently observed when participants read tool words (Chao et al., 1999), which argues against a role of this region in the processing of nouns semantically related to tools. Furthermore, some researchers have claimed that inferior frontal activation is unrelated to meaning but, instead, specifically associated with verb processing (e.g., Shapiro \& Caramazza, 2003), thus arguing against the relevance of frontocentral areas for nouns, tool names included. Therefore, the question about activation of premotor cortex related to the meaning of nouns is still open.

The goal of this study was to explore the role of sensory and motor knowledge in shaping the cortical underpinnings of concrete noun meaning. We adopted a passive task, in which participants were requested to silently read nouns that referred to tools, foods, and animals.
To avoid task-related motor activity, which may mask semantically related sensorimotor activity, participants were not required to make overt responses in the experiment, although their performance was assessed in a verbal memory test after experiment completion. Event-related fMRI was used to obtain brain responses to the three semantic noun categories. Stimuli were selected according to their semantic properties, as assessed empirically using semantic ratings (see Pulvermüller, Lutzenberger, \& Preissl, 1999), and matched for a range of psycholinguistic variables. We hypothesized that, even in the case of nouns that do not refer to actions, a degree of dorsal stream motor system involvement might be manifest. According to the cell assembly model of semantic circuits (Pulvermüller \& Fadiga, 2010; Pulvermüller, 1999), such motor system activations should reflect semantic features, which would derive indirectly from the action implications of the objects to which the words refer. Tool words refer to objects that are typically manipulated with the hand. Food words refer to objects that afford mouth activity, and, to a lesser degree, hand-arm activity too. In contrast, most animal words, as confirmed by semantic ratings, do not typically show such conceptual relationships to actions. We therefore predicted differential activation of cortical motor systems by tool and food words, but not or to a lesser extent by animal words. We also re-examined previously reported results on brain activation differences between animal and tool word categories observed in the naming task (Martin, 2007).

\section{METHODS \\ Participants}

Eighteen healthy volunteers participated in the study. All participants were right-handed (laterality quotient of 90, $S E=3.1$; Oldfield, 1971), monolingual English native speakers. Their mean age was 29 years $(S E=2.8)$. Participant had no history of neurological or psychiatric disorders. They had normal or corrected-to-normal vision. IQ scores were above average (mean $=110, S E=3.0$; Cattell \& Cattell, 1960). All participants gave their informed consent to take part in the study and were remunerated for their time. Ethical approval was obtained from the Cambridge Psychology Research Ethics Committee.

\section{Experimental Procedure}

One hundred twenty (120) object words, 40 from each individual category of tool-, animal-, and food-related words, were selected based on semantic criteria and matched for a range of psycholinguistic criteria. Ratings of word meaning were obtained from 10 English native speakers, using questionnaires (see Pulvermüller et al., 1999). On a 7-point rating scale, participants had to rate the meaning of potential stimulus words with regard to a number of semantic variables, including (1) sensorimotor semantic features such as imageability, concreteness, and semantic relationship to 
action and bodily sensation and (2) emotional-affective features, such as arousal, valence, and general emotionrelatedness. Stimulus word groups were matched (van Casteren \& Davis, 2007) for word length (counted in number of letters), letter bigram and trigram frequency, logarithmic word frequency, number of orthographic neighbors, and standardized lexical frequency (see Behavioral Results). Relevant values were obtained from the CELEX database (Baayen, Piepenbrock, \& van Rijn, 1993) and the WordSmyth Web site (www.wordsmyth.net/). Most stimulus words were lexically unambiguous nouns; the few lexically ambiguous items in each category group had their dominant use as nouns as confirmed by data from CELEX. The three noun categories differed in the ratings of their semantic association to objects, actions, bodily sensations, emotional features, concreteness, and imageability (see Behavioral Results). The 120 stimulus words were interspersed in-between 240 filler words of various types to prevent participants from focusing their minds on noun or object processing. Strings of meaningless hash marks matched in length to the stimulus words were used as low-level baseline stimuli during 120 trials. Statistical comparisons were carried out between brain activation patterns elicited by matched word categories.

Stimuli were presented for $150 \mathrm{msec}$ each. Between two consecutive stimuli, a fixation cross was presented at the center of the screen. The SOA between successive word/hashmark stimuli was $2.5 \mathrm{sec}$, and the scanning repetition time was $2 \mathrm{sec}$, resulting in a difference of $0.5 \mathrm{sec}$. Pseudorandomized sequences of stimuli were created using the "Mix" program (van Casteren \& Davis, 2006), and two different lists were alternated between participants. Stimuli were delivered by means of E-Prime software (Psychology Software Tools, Inc., Sharpsburg, PA) through a back-projection screen positioned in front of the scanner and viewed on a mirror placed on the head coil. Participants were given the instruction to attend to all the stimuli, to silently read the words, and to understand their meaning. For statistical analysis, the SPM5 canonical hemodynamic response function was used to model the time course of activation for hash mark strings, filler words, and each of the three word categories.

To identify motor cortex activation, a motor localizer task was administered in a separate block. During localizer trials, the words "tongue," "left finger," "right finger," "left foot," "right foot," and "rest" appeared on a computer screen for $10 \mathrm{sec}$, and participants had to execute the corresponding movement during the whole period that the item remained on the screen. Between trials, a fixation cross appeared for $0.5 \mathrm{sec}$. Two pseudorandomized sequences of stimuli were alternated between participants.

A short word recollection test containing a combination of 50 experimental and 25 novel distractor words was given to participants after scanning to assess whether participants had been constantly attentive during the silent reading task.

\section{Imaging Methods and Data Analysis}

Participants were scanned in a Siemens 3T Tim Trio using a head coil. EPI sequence parameters were as follows: repetition time $=2000 \mathrm{msec}, \mathrm{TE}=30 \mathrm{msec}$, and flip angle $=$ $78^{\circ}$. The functional images consisted of 32 slices covering the whole brain (slice thickness $=3 \mathrm{~mm}$, in-plane resolution $=3 \times 3 \mathrm{~mm}$, interslice distance $=0.75 \mathrm{~mm}$ ). Imaging data were processed using SPM8 software (Wellcome Department of Imaging Neuroscience, London, UK).

Images were corrected for slice timing and realigned to the first image using sinc interpolation. The EPI images were coregistered to the structural T1 images using a mutual coregistration procedure (Maes, Collignon, Vandermeulen, Marchal, \& Suetens, 1997). The structural MRI was normalized to the 152-participant T1 template of the Montreal Neurological Institute (MNI). The resulting transformation parameters were applied to the coregistered EPI images. During spatial normalization, images were resampled with a spatial resolution of $2 \times$ $2 \times 2 \mathrm{~mm}^{3}$. Normalized images were spatially smoothed with an 8-mm FWHM Gaussian kernel and globally normalized. Single-participant statistical comparisons were computed by using the general linear model (Friston et al., 1998).

Low-frequency noise was removed by applying a highpass filter of 128 sec. Group data were analyzed using random effects analysis. Brain activation to words was first compared statistically against the low-level baseline condition (hash marks). Whole-brain analysis results are visually displayed at a false discovery rate (FDR)-corrected threshold $(p<.05)$ and at a more lenient uncorrected threshold $(p<.001$, cluster size $>33$ voxels). Stereotaxic coordinates for voxels with maximal $t$ values within activation clusters are reported in the MNI standard space (Table 1).

In addition to whole-brain voxel-by-voxel analysis, a set of ROIs were scrutinized statistically for word category effects. A first analysis focused, in a data-driven manner, on 10 ROIs from the whole-brain random effect analysis contrasting activation to all the object-related words against that to hash mark strings (Table 2). Six of these loci were the maximally active ones (highest $t$ values) and four additional peaks, taken from the same contrast, were close to previously reported loci of word category effects, in the left orbito-frontal, the right lateral central, and the right fusiform-cerebellar regions (Hauk, Johnsrude, \& Pulvermüller, 2004; Chao et al., 1999, 2002). For each ROI, average activation in spheres of $2-\mathrm{mm}$ radius was calculated for each word category for these loci and an ANOVA (10 ROIs $\times 3$ Word Categories) was calculated. Note that, because an 8-mm smoothing kernel was used, a 2-mm radius ROI led to a half-maximum width of $12 \mathrm{~mm}$. This size was chosen to enable comparison of ROIs situated close to each other while still pooling data from several voxels to increase signal-to-noise ratios. Guided by results from the motor localizer scans for finger and 
Table 1. Psycholinguistic Properties and Semantic Ratings Are Shown for All Three Word Categories, Animal, Food, and Tool Nouns

\begin{tabular}{|c|c|c|c|c|}
\hline & Tool Words & Animal Words & Food Words & Main Effect of Word Type (F) \\
\hline Length (letters) & $4.375(0.117)$ & $4.275(0.107)$ & $4.375(0.099)$ & $0.429(p<.6)$ \\
\hline Length (syllables) & $1(0)$ & $1(0)$ & $1(0)$ & NA \\
\hline Bigram frequency & 38264.935 (3188.7) & $34618.395(2779.8)$ & 40530.08 (2232.8) & $1.207(p<.3)$ \\
\hline Trigram frequency & $4143.261(835.8)$ & $4454.728(497.4)$ & $3852.258(323.09)$ & $0.268(p<.7)$ \\
\hline No. of neighbors & $7.2(0.817)$ & $8.75(0.942)$ & $8.025(0.893)$ & $0.770(p<.5)$ \\
\hline No. of meanings & $1.225(0.104)$ & $1.575(0.142)$ & $1.175(0.079)$ & $3.632(p<.03)$ \\
\hline Logarithmic word frequency & $.7856(0.077)$ & $.78211(0.070)$ & $.7852(0.079)$ & $0.153(p<.9)$ \\
\hline Imageability & $5.475(0.207)$ & $6.297(0.107)$ & $5.585(0.179)$ & $6.857(p<.001)$ \\
\hline Concreteness & $5.825(0.131)$ & $6.592(0.057)$ & $6.249(0.124)$ & $12.931(p<.001)$ \\
\hline Action relatedness & $2.971(0.241)$ & $1.625(0.130)$ & $1.692(0.151)$ & $17.983(p<.001)$ \\
\hline Face relatedness & $1.236(0.062)$ & $1.226(0.053)$ & $2.010(0.176)$ & $16.253(p<.001)$ \\
\hline Arm relatedness & $2.735(0.196)$ & $1.13(0.052)$ & $1.365(0.085)$ & $42.628(p<.001)$ \\
\hline Body sensation & $1.369(0.087)$ & $1.106(0.034)$ & $1.316(0.067)$ & $4.270(p<.016)$ \\
\hline Valence & $3.798(0.066)$ & $3.714(0.054)$ & $4.049(0.083)$ & $6.085(p<.003)$ \\
\hline Arousal & $1.511(.083)$ & $1.268(.094)$ & $1.429(.099)$ & $1.654(p<.195)$ \\
\hline
\end{tabular}

Means and standard errors (in parentheses) are reported for each word category, along with results of an ANOVA comparing ratings between word groups.

tongue movements, a further ROI analysis of precentral cortex was carried out. An additional ANOVA looked at activations elicited by the word categories in these regions (Design: 2 ROIs $\times 3$ Word Categories).

With the aim of establishing the contribution of inferior temporal and fusiform circuits, which have previously been found active differentially in tasks of tool and animal naming, we further scrutinized temporal regions with peak activation in the whole-brain analysis (all object words against baseline). As three foci and peak activation voxels were found in inferior temporal and fusiform cortex on the left and three additional peaks were located in the adjacent cerebellum in the right hemisphere (sometimes with activity overspilling to inferior temporal areas), we included six ROIs centered around these. ANOVA contrasted activation in these ROIs between word groups (3 Word Categories $\times 6$ ROIs) and grouped these regions into the factors Laterality, with three ROI levels on each side (3 Word Categories $\times 2$ Laterality $\times 3$ ROIs). To all ANOVA results, Huynh-Feldt correction was applied to correct for sphericity violations. In this case, epsilon values and corrected $p$ values are reported throughout.

An additional voxelwise analysis was performed within the motor regions that were active to object words against baseline by using small volume correction.

\section{RESULTS}

\section{Behavioral Results}

To evaluate the relationship between sensorimotor semantic properties and the three semantic noun cate- gories, results of the semantic rating experiment were evaluated in detail. A two-way ANOVA investigated the ratings of general action-relatedness, face action-relatedness, and arm action-relatedness for the words in the noun categories (animal, food, tool). A significant interaction between the factors Action Feature and Noun Category $[F(2,117)=52.77, p<.001]$ showed that food words were rated to be more strongly related to face, but not hand, actions than the other two noun categories, whereas tool words were rated to be most strongly linked to actions performed with the hand or arm (Figure 1); tool words were also judged to be more strongly related to actions generally $[F(2,117)=17.98, p<$ $.001]$ and to bodily sensations compared with the other two categories $[F(2,117)=4.27, p=.016]$. Ratings of affective-emotional meaning indicated a more positive valence for food words as compared with the other two categories $[F(2,117)=6.08, p=.003]$. Food words were also special because they received higher ratings than the other two word types for semantic links to taste-odor [main effect: $F(2,115)=183.54$, $p<.001]$ and color information $[F(2,117)=32.67$, $p<.001]$.

Whereas tool and food words dominated in the action domain, animal words received higher ratings of imageability $[F(2,117)=6.85, p=.0015]$, concreteness $[F(2$, $117)=12.93, p<.001]$, semantic links to visual information $[F(2,117)=5.76, p=.004]$, and form $[F(2,117)=$ $6.35, p=.002]$ than the other two stimulus word groups. Also the average number of meanings of words was slightly higher for animal names than for tools or foods. 
Semantic rating results are summarized in Figure 1, and some of them are related to brain dynamics in subsequent figures. Mean values and standard errors for both semantic properties, for which word groups differed, and psycholinguistic variables, for which they were matched, are also summarized in Table 1.

In the word recognition test administered after the fMRI experiment, performance was clearly above chance in all participants evaluated (average hit rate: $76.2 \%, S E=$ $4.2 \%$; false positive rate: $56.8 \%, S E=5.2 \%$ ). Together with the language-related brain activations obtained, these results are evidence that participants had been attentive during the passive reading experiment.

\section{fMRI Results: Whole-brain Analyses}

Comparison of all object words against baseline (Figure 2; Table 3 ) revealed most prominent clusters of activation in the left inferior frontal gyrus ("peak voxel" in the left inferior frontal gyrus, pars triangularis of Broca's area, BA 45, at MNI standard stereotaxic coordinates -48426 ), the posterior section of the left superior and middle temporal

Table 5.2

Table 2. MNI Coordinates for the fMRI Activation Contrasts between All Object Words and Baseline

\begin{tabular}{|c|c|c|c|}
\hline & $x y z$ & Cluster Extent (Voxel) & $t$ \\
\hline \multicolumn{4}{|l|}{ All Object Words } \\
\hline Left inferior frontal gyrus (BA 45) & -48426 & 1799 & 7.54 \\
\hline Left inferior frontal gyrus & $-3430-16$ & & 6.39 \\
\hline Left middle orbital gyrus & $-2432-16$ & & 6.25 \\
\hline Left precentral gyrus (BA 6, BA 4, BA 1) & $-46-846$ & 506 & 7.03 \\
\hline Left precentral gyrus (BA 6, BA 44) & -56436 & & 4.17 \\
\hline Left postcentral gyrus (OP 4, BA 3, BA 1) & $-58-1222$ & 26 & 4.16 \\
\hline Left precentral gyrus (BA 44, BA 6, BA 3) & -58620 & 34 & 4.07 \\
\hline Left precentral gyrus (BA 6, BA 44, BA 3) & -60628 & & 3.82 \\
\hline Left precentral gyrus (BA 6) & $-30-854$ & 15 & 4.02 \\
\hline Right inferior frontal gyrus (pars orbitalis) & $3436-12$ & 39 & 4.52 \\
\hline Right precentral gyrus & 60238 & 85 & 5.30 \\
\hline Right precentral gyrus (BA 6) & $34-856$ & 46 & 4.25 \\
\hline Right precentral gyrus (BA 6, BA 4) & $32-1854$ & & 3.80 \\
\hline Left temporal pole & $-5610-10$ & 26 & 4.58 \\
\hline Left middle temporal gyrus & $-58-382$ & 330 & 7.22 \\
\hline Left inferior temporal gyrus & $-46-40-16$ & 613 & 6.97 \\
\hline Left inferior temporal gyrus & $-46-60-10$ & & 6.03 \\
\hline Left fusiform gyrus & $-38-34-20$ & & 5.60 \\
\hline Left fusiform gyrus & $-38-12-26$ & 23 & 4.85 \\
\hline Left inferior parietal lobule (IPC-PF, IPC-PFthIP2) & $-56-3440$ & 77 & 4.32 \\
\hline Left inferior parietal lobule (IPC, hIP2, BA 2) & $-48-3038$ & & 4.01 \\
\hline Left postcentral gyrus (BA 2, BA 1) & $-44-2650$ & & 4.01 \\
\hline Left supramarginal gyrus (IPC BA 40) & $-52-4026$ & 56 & 4.93 \\
\hline Left postcentral gyrus (IPC) & $-64-2034$ & 19 & 4.14 \\
\hline \multirow[t]{2}{*}{ Right cerebellum (Lobule VI Hem, Lobule VIIa Crus) } & $38-50-30$ & 44 & 4.51 \\
\hline & $8-54-6$ & 26 & 4.18 \\
\hline Right cerebellum (Lobule V, Lobule VI) & 2082 & 29 & 4.32 \\
\hline
\end{tabular}

In all tables, coordinates are reported at a significance level of $p<.001$ (uncorrected). Activations at coordinates $-48426,-3430-16,-2432-16$, $-46-846,-56436$ (highlighted in bold) survived topological FDR correction as well as FWE correction at $p<.05$ in SPM8. In all figures, indented coordinates are part of larger clusters. Brodmann's areas with highest probability in anatomy are reported. 
Figure 5.1

Figure 1. Semantic ratings (means and standard errors) for tool (in red), animal (blue) and food nouns (green). Ratings of imageability, concreteness, and semantic relatedness to actions generally, face-mouth actions, arm-hand actions, bodily sensations, affectiveemotional arousal, and valence.

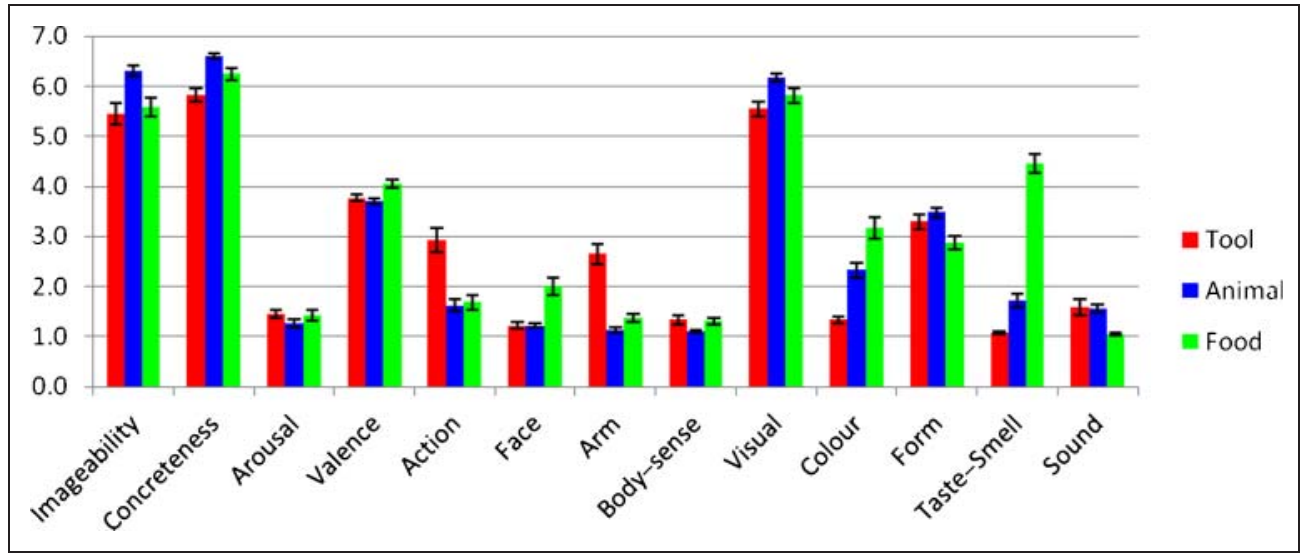

gyrus ( $-58-382$, BA 22), and the sensorimotor cortex including precentral and postcentral gyrus and central sulcus. Central activation was bilateral but stronger in the left dominant hemisphere ("peak voxel" at $-46-8$ 46, BA 6/ premotor cortex) than in the right $(62-1040$, BA 3). Additional activation foci common to all object words were located in the left posterior inferior temporal cortex $(-46-40-16$, BA 21) and fusiform gyrus ( $-38-12$ -26 , BA 20).

Activation patterns specific to each individual noun category (tool, animal, food) against baseline (viewing hash marks) are reported in Table 4. A large cluster of activation to food-related words was observed in the central sensorimotor cortex bilaterally, although fMRI response was more widespread in the language-dominant left hemisphere $(-50-1044$, BA 4), which included the inferior left postcentral gyrus corresponding to the face area. In addition, food words recruited the left inferior frontal gyrus (Broca's area, pars opercularis, BA 44, -34 10 30) and the left OFC ( $-3430-16$, BA 47). Left ventrolateral inferior temporal cortex $(-42-12-26$, BA 20) and fusiform gyrus were also found to be activated by food words. Silent
Figure 2. (A) Significant activations elicited by all object words (tool, animal, and food words) compared with the hash mark baseline condition. Activations are plotted at an FDR-corrected significance level of $p<.05$. Results are rendered on a standard brain surface. Hemodynamic activation in the right hemisphere involved right precentral and postcentral motor areas (MNI coordinates: 602 38, $34-8$ 56, $32-18$ 54; diagram on the left). Left hemisphere activity was present in the precentral $(-58620)$ and postcentral gyrus $(-46-846)$, the superior frontal cortex $\left(\begin{array}{lll}-18 & 18 & 44\end{array}\right)$, the left middle frontal (-30 48 8) and left inferior frontal gyrus ( -48426 ), the superior temporal pole $(-5610-10)$, the middle $(-58-382)$ and inferior temporal cortices $(-46-40$ $-16)$, and the left supramarginal gyrus $(-52-4026$; see also Table 3). The activation foci of this contrast were used to define ROIs for further statistical analyses. (B) Activations for tongue (green) and finger movements (red) from the motor localizer experiment.

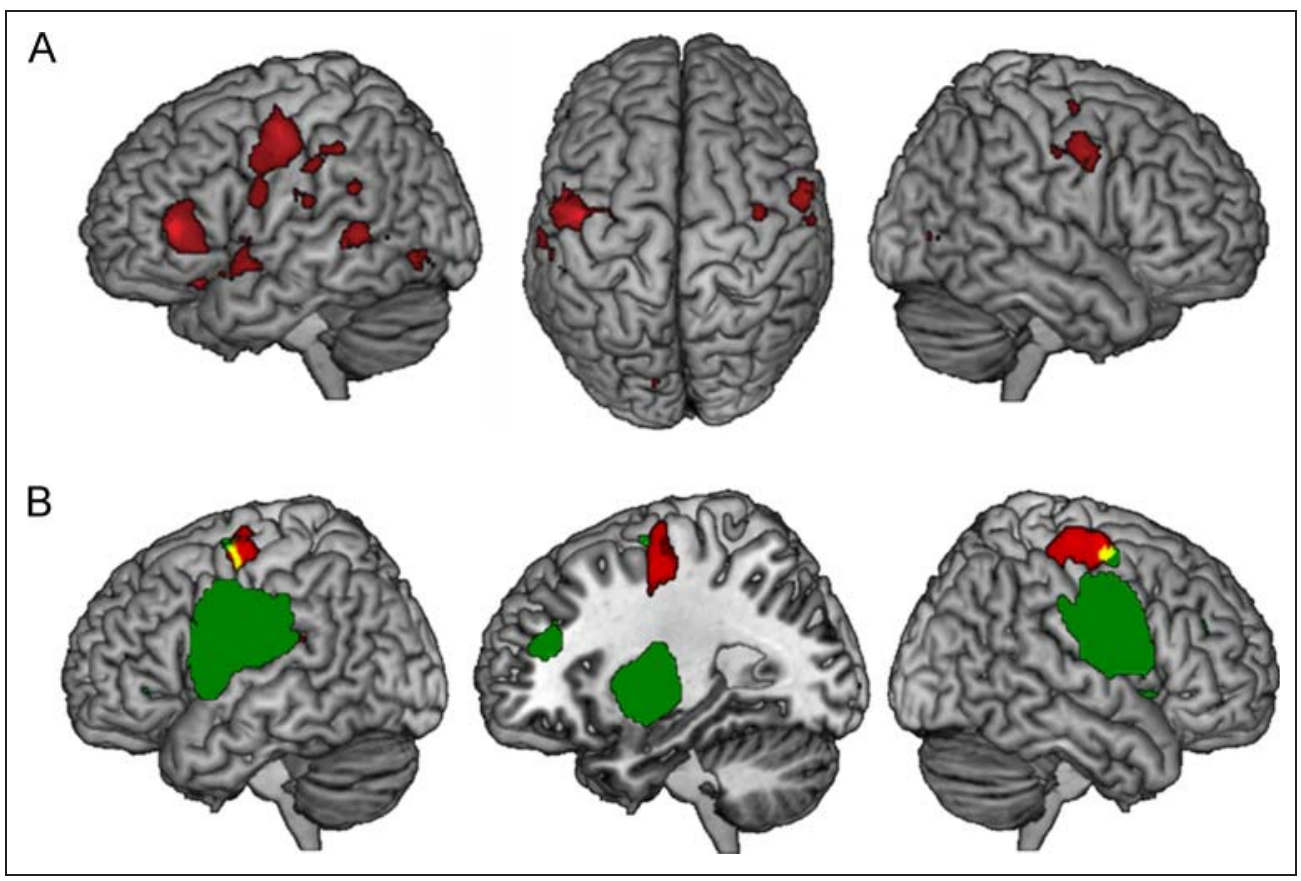


Table 5.3

Table 3. MNI Coordinates for the Contrasts Tool Words against Baseline, Animal Words against Baseline, and Food Words against Baseline

xyz Cluster Extent (Voxel)

$t$

Tool Words

Left inferior frontal gyrus (BA 45)

$-48386$

130

6.02

Right rolandic operculum (OP3, OP4, BA 44)

52014

41

4.74

44216

4.26

Left insula (BA 48)

$-30304$

5.59

Left precentral gyrus (BA 44, BA 3)

$-56416$

132

4.10

Left precentral gyrus (BA 6)

$-30-852$

4.64

Left postcentral gyrus (BA 6, BA 4, BA 1)

$-46-844$

4.58

Left precentral gyrus (BA 6)

$-54-244$

3.82

Right precentral gyrus (BA 6)

$32-856$

4.20

Left superior temporal gyrus (TE 1.1, OP)

$-50-284$

4.62

Left temporal pole

$-5610-10$

4.34

Left middle temporal gyrus

$-56-362$

4.13

Left inferior temporal cortex (Hipp)

$-40-32-14$

4.87

Left inferior temporal gyrus

$-46-40-16$

4.37

Left fusiform gyrus

$-38-44-24$

4.18

Right cerebellum (Lobule VII, Lobule VII Crus)

$38-48-32$

120

5.74

Left putamen

$-26126$

Left putamen

Left supramarginal gyrus (IPC, hIP2)

$-20412$

4.33

$-52-3826$

4.77

Left inferior parietal lobule (IPC, hIP2, Area2)

$-54-2632$

Right cerebellum (Lobule VI, Lobule VII Crus)

$-50-3236$

Right cerebellum (Lobule VII, Lobule VII Crus)

$38-48-32$

\section{Animal Words}

Left inferior frontal gyrus (pars orbitalis)

Left inferior frontal gyrus (pars triangularis)

Right middle frontal gyrus

Left middle temporal gyrus (TE3)

\begin{tabular}{lll}
$-2632-12$ & 129 & 5.84 \\
-46404 & 114 & 4.74 \\
365018 & 112 & 4.90 \\
$-58-360$ & 124 & 4.74 \\
$-64-404$ & & 4.19 \\
-423020 & 1106 & 5.89 \\
$-46-2420$ & & 5.10 \\
$-38-44-22$ & 277 & 5.76 \\
$-38-34-20$ & & 5.18 \\
$-34-6830$ & & 4.85 \\
$-30-7836$ & 54 & 4.36 \\
$18-8024$ & & 4.21 \\
\hline
\end{tabular}

Left inferior frontal gyrus (BA 45, 44)

Left rolandic operculum (OP1, TE1, OP3, IPC, TE)

Left fusiform gyrus (BA 20)

Left middle occipital cortex (IPC-PGa)

Left middle occipital gyrus (SPL, IPC)

Right cuneus (BA 19)

$18-8024$

4.21 
Table 3. (continued)

\begin{tabular}{|c|c|c|c|}
\hline & $x y z$ & Cluster Extent (Voxel) & $t$ \\
\hline \multicolumn{4}{|l|}{ Food Words } \\
\hline Left inferior frontal gyrus (pars orbitalis) & $-3430-16$ & 203 & 7.39 \\
\hline \multirow[t]{2}{*}{ Left inferior frontal gyrus (pars opercularis, BA 44) } & -341030 & 118 & 4.60 \\
\hline & -441028 & & 4.31 \\
\hline Left inferior frontal gyrus (pars triangularis, BA 45) & -48406 & 31 & 4.55 \\
\hline \multirow[t]{3}{*}{ Left postcentral gyrus (BA 4, BA 6, BA 1, BA 3, BA 2) } & $-50-1044$ & 569 & 6.05 \\
\hline & $-56-1044$ & & 5.02 \\
\hline & $-38-2042$ & & 4.93 \\
\hline Right precentral gyrus (BA 6, BA 44) & 58440 & 90 & 4.98 \\
\hline Right precentral gyrus (BA 6, BA 4) & $34-1852$ & 83 & 4.83 \\
\hline Left middle temporal gyrus & $-56-382$ & 312 & 8.26 \\
\hline Left inferior temporal cortex & $-42-12-26$ & 48 & 6.08 \\
\hline Left inferior occipital cortex & $-44-60-10$ & 465 & 6.99 \\
\hline Left inferior temporal cortex & $-46-40-14$ & & 6.07 \\
\hline Left fusiform gyrus & $-38-34-20$ & & 5.74 \\
\hline
\end{tabular}

reading of tool-related words sparked the left hand premotor cortex in precentral gyrus $(-30-8-54$, BA 6) along with the right fusiform $(38-48-32)$ and cerebellar area $(6-50-32)$ activation. Activity to animal words tended to dominate in the left dorsolateral pFC, encompassing the left inferior frontal gyrus ( -46404 , BA 45) and ventromedial pFC ( $-2632-12$, BA 11) and in the left temporal (-4230 20, BA 48) and cerebellar regions (8 -58 -22). Premotor and motor regions seemed to be relatively spared, although animal words activated the postcentral gyrus ( $-46-2452$, BA 3).

For the localizer tasks, comparison of tongue movements against baseline (rest condition) showed activation of the left and right central sulcus (-58 - 430 and 64030 , BA 4), the left middle temporal gyrus ( $-50-622$, BA 37), the left superior parietal cortex $(-18-6454$, BA 7), and the bilateral cerebellum ( $-18-62-20,20-64-20)$. Finger movements as compared with rest activated the left and right precentral gyrus (respectively at MNI coordinates $-34-654$ and $44-660$, BA 6), the left middle occipital cortex $(-18-982$, BA 18), the right lingual gyrus (22 -86 -4, BA 18), and the cerebellum bilaterally (left: $-16-52-18$, right: $24-52-24)$.

\section{Word Category Differences and ROI Analyses}

To obtain an unbiased estimate of word-related activation, we first explored the contribution of the premotor and motor activation clusters that were active to all object words against baseline after applying topological FDR correction $(p<.05$ at cluster level; Chumbley, Worsley,
Flandin, \& Friston, 2010; Chumbley \& Friston, 2009). Two spheres of $20-\mathrm{mm}$ radius and $10-\mathrm{mm}$ radius were placed, respectively, around the upper maximal activation cluster at coordinates $-46-846$ and around the lower maximal activation cluster at coordinates -56436 . Spheres of different sizes were used to capture the large lateral premotor/precentral activation focus and the somewhat smaller focus in the inferior frontal Broca's area (see Figure 2A). Voxelwise analysis within the individual word category spaces was conducted by applying small volume correction to these spheres adopting the family-wise error (FWE) correction procedure (Friston, 1997; Worsley et al., 1996). In the upper cluster, we found a significant activation for the contrast "tool against baseline" at a peak voxel $-30-854$ (FWE-corrected $p=.044$ ), but not for the other word category. In the lower sphere, we observed a significant activation for the contrast "food against baseline" at a peak voxel -60628 (FWE-corrected $p=.001$ ), but not for the other categories. Additional loci within these spheres were activated by both tool and food words to the same degree.

To assess the direct contrast between the local activations elicited by the individual semantic word categories in the frontocentral, temporal, and cerebellar regions, an ANOVA was performed (ROI $\times$ Word Category) on 10 ROIs. Six of these ROIs were centered at prominent activation peaks obtained from the comparison of all object words to baseline, and four were guided by category differences reported in previous experimental studies (see Methods). This ANOVA revealed a significant interaction of factors ROI and Word Category $[F(18,306)=1.653$, 
Table 5.4

Table 4. MNI Coordinates for the Contrasts Tongue and Finger Movement against Baseline

\begin{tabular}{|c|c|c|c|}
\hline & $x y z$ & Cluster Extent (Voxel) & $t$ \\
\hline \multicolumn{4}{|l|}{ Tongue } \\
\hline Right precentral gyrus (BA 6, BA 1, BA 3, BA 4) & 64026 & 43766 & 12.98 \\
\hline Right postcentral gyrus (BA 3, BA 4, BA 2) & $56-1026$ & & 12.63 \\
\hline Left postcentral gyrus (BA 3, BA 4, BA 3) & $-56-828$ & & 11.94 \\
\hline Left middle temporal gyrus (hOC5-V5) & $-50-622$ & 96 & 3.42 \\
\hline Left cerebellum (Lobule VIII) & $-18-64-58$ & & \\
\hline Left cerebellum (Lobule VI, Lobule V) & $-18-62-20$ & 451 & 7.55 \\
\hline Right cerebellum (Lobule VI, Lobule VII) & $20-64-20$ & 473 & 7.32 \\
\hline \multicolumn{4}{|l|}{ Fingers } \\
\hline Left precentral gyrus (BA 6) & $-36-460$ & 2747 & 8.70 \\
\hline Left superior frontal gyrus (BA 6) & $-30-868$ & & 7.96 \\
\hline Left SMA (BA 6) & $-6-458$ & & 6.04 \\
\hline Left precentral gyrus (BA 6, BA 44, BA 3) & -60628 & & 6.11 \\
\hline Right precentral gyrus & $42-662$ & 2095 & 8.65 \\
\hline Left postcentral gyrus (IPC-PFop, OP1, IPC-PFt) & $-60-2226$ & 1301 & 6.11 \\
\hline Left inferior parietal lobule (IPC, BA 2, BA 1) & $-56-2438$ & & 5.34 \\
\hline Left middle occipital (BA 18, hCO3, BA 17) & $-18-1000$ & 361 & 5.74 \\
\hline Right middle occipital gyrus (BA 17, hCO3, BA 18) & $24-966$ & 168 & 5.56 \\
\hline Left putamen & $-26-44$ & 560 & 4.71 \\
\hline Left insula lobe & -40012 & & 4.70 \\
\hline Right putamen & $28-22$ & 297 & 4.65 \\
\hline Left cerebellum (Lobule VI, Lobule V) & $-18-52-22$ & 108 & 4.36 \\
\hline Right cerebellum (Lobule VI, Lobule V) & $20-52-22$ & 113 & 4.17 \\
\hline
\end{tabular}

$p<.0469$ ], suggesting that the targeted brain regions were activated to different degrees by the three semantic word categories. However, this interaction effect was only marginal after correction for sphericity violations $(\mathrm{HF}-\varepsilon=$ $0.680, p<.0779$ ), thus weakening the support for topographical differences between brain activation patterns elicited by the different word categories. Furthermore, ANOVAs were therefore run to target-specific brain parts in a theory-driven manner.

An analysis of motor system activations was guided by ROIs activated during localizer tasks, when participants moved their tongue or left index finger, respectively. Prominent activation maxima in premotor cortex were found for tongue movements at MNI coordinates - 56 -828 and for left index finger movements at $-36-4$ 60. These peaks were closely matched-especially in $x$ and $z$ coordinates-by precentral activation peaks observed in the "All object words against baseline" contrast, wherein local maxima emerged at -60628 (14 mm anterior to the tongue localizer maximum) and $-30-854$
( $8 \mathrm{~mm}$ away from the finger localizer maximum). Use of these latter ROIs in a comparison between word categories (design: ROI (face vs. finger area) $\times$ Word Category (animal vs. food vs. tool) yielded a significant interaction $[F(2,34)=4.18, \mathrm{HF}-\varepsilon=0.946, p<.0261]$. The differentially activated face and arm regions lay within the range of areas found in several previous studies to be particularly responsive to action words and sentences semantically related to the face and arms, respectively (for review, see Pulvermüller \& Fadiga, 2010; Kemmerer \& GonzalezCastillo, 2008). As Figure 3 shows, activity in the dorsolateral finger ROI was especially strong for tool words and activity in the inferior precentral tongue ROI was mainly driven by food words. Animal words elicited relatively weak activation in both motor ROIs. Individual analysis of these ROIs further confirmed main effects of word category. The inferior precentral tongue cortex $(-60,6,28)$ revealed significantly enhanced food word responses $[F(2,34)=4.182, p<.023]$, although direct comparison only confirmed the difference between food 


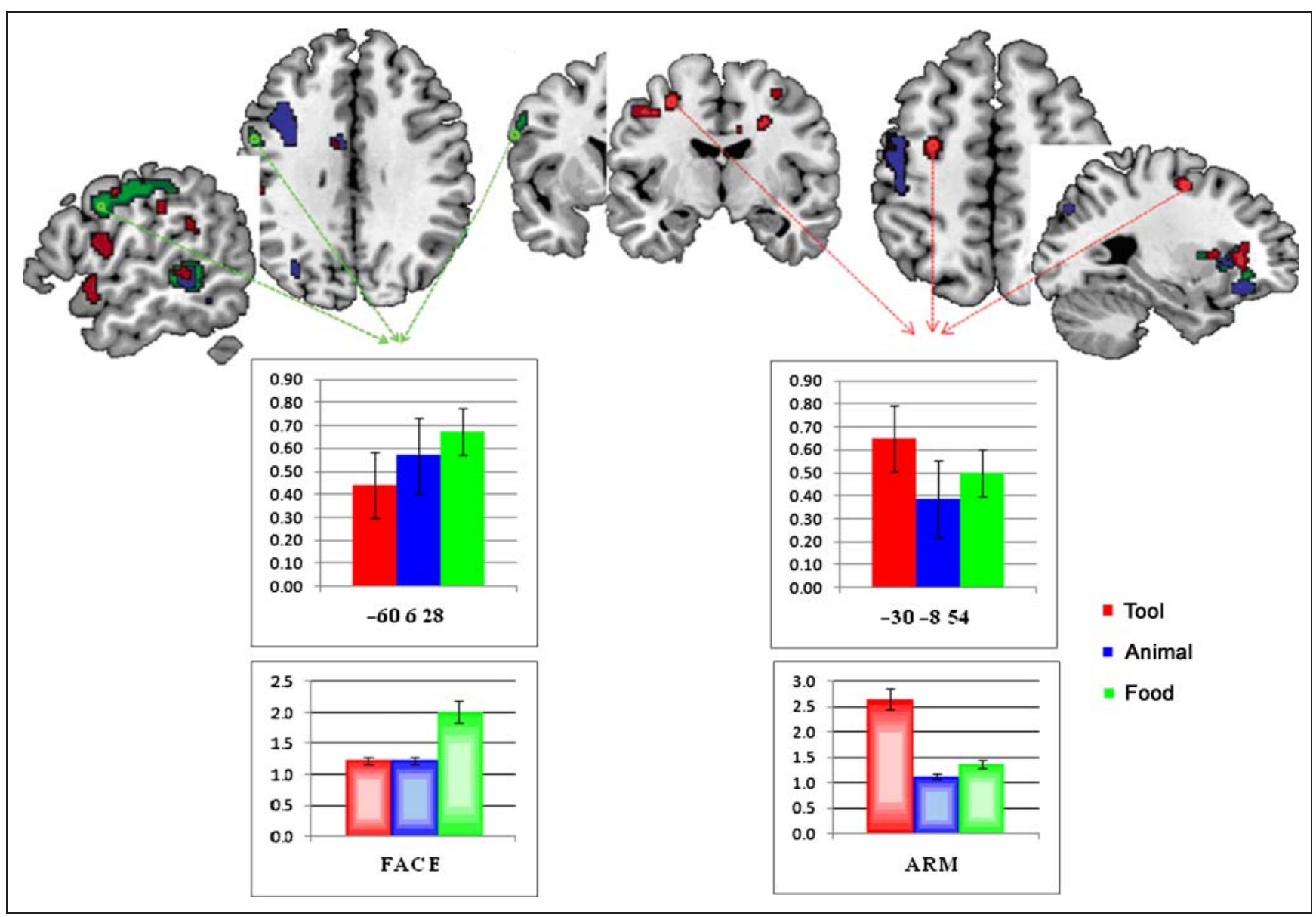

Figure 3. Category-specific somatotopic activity in the motor and premotor cortex to food words (green) and tool words (red). Food words

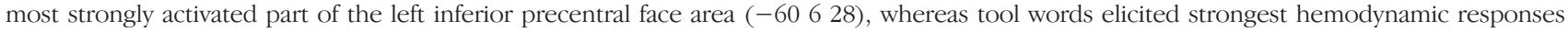
in dorsal precentral hand cortex $(-30-854)$. Activity to animal words is plotted in blue. Results are thresholded at a significance level of $p<.001$ (uncorrected). Bar graphs at the top give means and standard errors of activation in tongue and finger ROIs to each noun category. The bottom graphs give semantic ratings of face and arm relatedness of the same stimulus words.

versus tool words $(p<.05)$. Relatively enhanced activation to tool words was also confirmed in dorsolateral precentral finger cortex $(-30,-8,54)[F(2,34)=4.182, p<.023]$, where a significant difference between tool and animal words was also confirmed by a planned comparison $(p<$ .05). Importantly, an additional ANOVA from which animal word data were removed confirmed that the significant differential activation of arm and face regions was driven by the contrast between hand-related tool- and face-related food words $[F(1,17)=5.12, p<.037]$.

Guided by previous reports on inferior temporal categoryspecific effects to animal and tool concepts (Chao et al., 1999, 2002), an ROI analysis focusing on inferior temporal, fusiform, and adjacent cerebellar activation foci-which had been revealed by the "all object words against baseline" contrast-compared hemodynamic responses in three left temporal and three right cerebellar foci (see Methods). These left hemispheric foci lay in temporalfusiform cortex at coordinates $-46-40-16,-46-60$ -10 , and $-38-34-20$, whereas right hemispheric cerebellar ROIs included the coordinates $38-50-30,8-54$
-6 , and $24-62-24$. A significant interaction of the factors Laterality (right, left), ROI (3 on each side), and Word Category (3) revealed a significant Laterality $\times$ Word Category interaction $[F(2,34)=6.753$, HF $\varepsilon=0.982, p=.0036]$. There was a clear predominance of tool word activation in the right cerebellar ROIs and an activation advantage of animal words over other word types in the left inferior temporal and fusiform cortex. Temporo-cerebellar sample regions and their word-category-specific activation patterns are shown in Figure 4A and B.

Finally, Figure 4C shows word category specificity of activation in the left OFC. This ROI, centered at MNI coordinates $-3430-16$, was also taken from the general contrast of all object words against baseline. Although a main effect of Word Category just approached significance in this ROI $(p<.1)$, there was stronger activity to food words than to tool items $[F(1,117)=7.50, p<$ $.014]$, with the third word category ending up in-between. The rightmost slice in Figure 3 also suggests adjacent patches of activation for the three noun categories in the left inferior-OFC. This inferior frontal category mapping 
cannot, however, be strongly empirically confirmed, as an objective way of defining ROIs was not available in this case.

\section{DISCUSSION}

Passive reading of object-related nouns typically used to speak about animals, foods, and tools elicited general activity in a range of left hemispheric language regions (including inferior frontal, middle-superior temporal, and inferior temporal-fusiform areas) and additional, specific, and unique patterns of activity in the left precentral cortical motor systems, the orbito-frontal areas, the inferior temporal cortex, and the right cerebellum. Specific activity in both dorsal and ventral streams was systematically linked in a category-specific manner to semantic aspects of the word types under study. Dorso- lateral precentral cortex near the somatotopic motor finger representation showed strongest activity to tool words, whereas food words dominated the hemodynamic response in inferolateral precentral areas near the tongue representation, consistent with the body parts most typically involved in manipulating the referent objects-hand for tools and mouth for food. Other activation foci also showed category-specific activation patterns that made sense in terms of word semantics. Right cerebellar activation contralateral to the most strongly involved precentral cortex was especially pronounced for tool words, consistent with the high ratings these items had received when participants judged their semantic links to actions generally. Orbito-frontal activity predominated for food words, which were also, consistently, given higher affectiveemotional valence ratings than the other word categories examined. Hemodynamic responses in the left inferior Figure 5.4

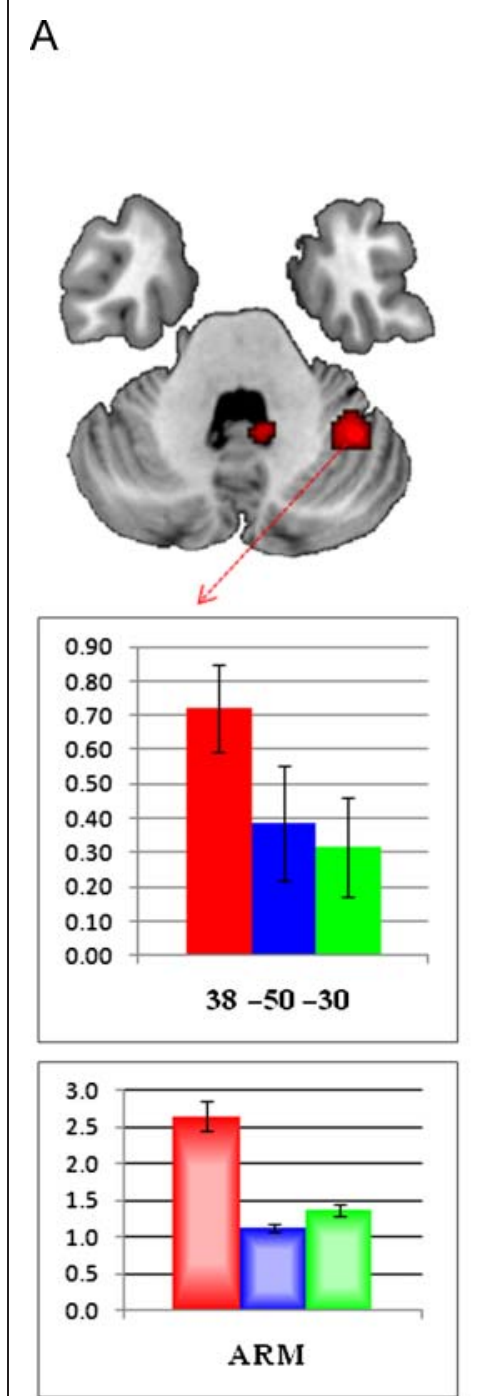

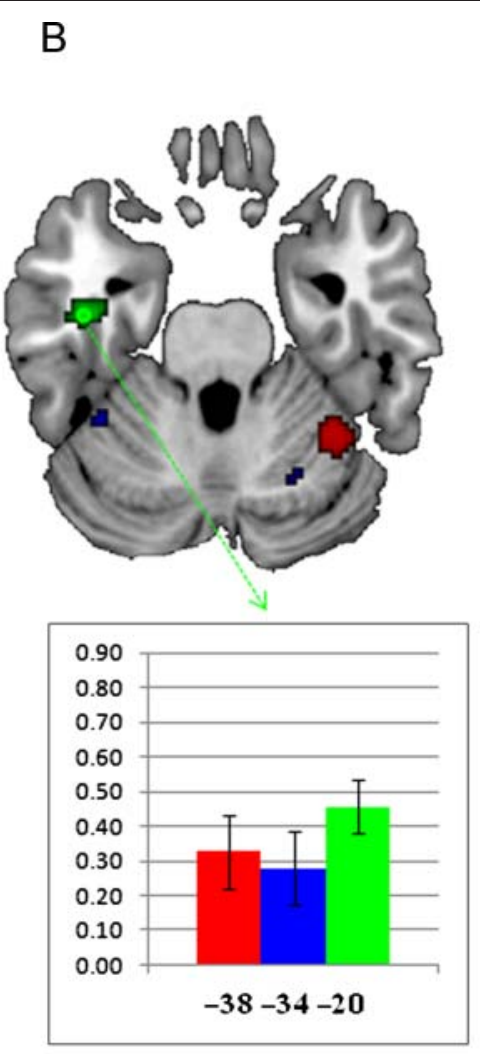

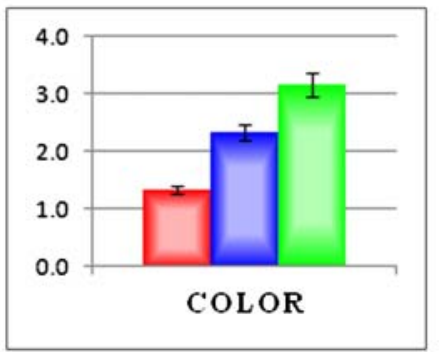

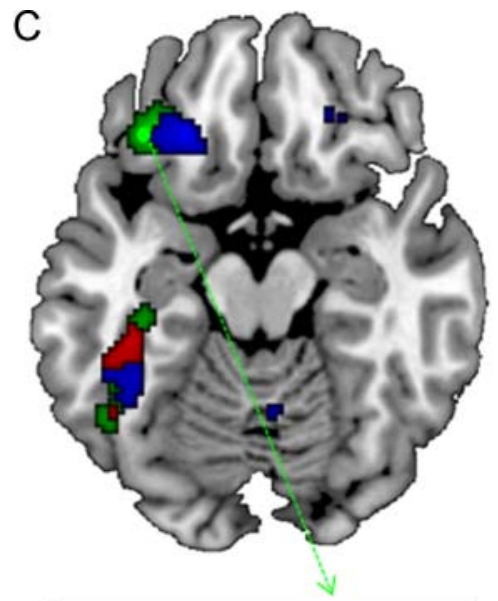
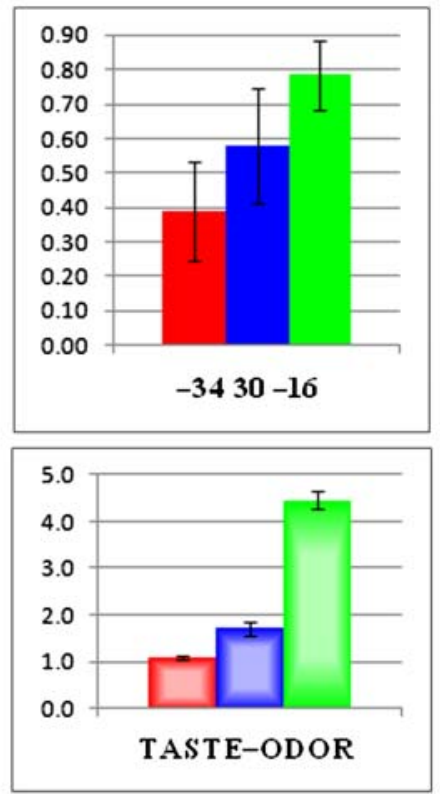

- Tool

- Animal

Food

Figure 4. Patterns of activation to three categories of nouns in the right cerebellum (A), the left fusiform cortex (B), and the left OFC (C). MNI coordinates are given for each relevant ROI. Brain slices display, bar graphs, and color coding as in Figure 3. Tool words activation predominated in the right cerebellum. Note a trace of semantic topography in the left OFC and left fusiform activation to food words. Bar graphs give ROI activity (top) and semantic ratings (bottom) for each noun category. 
temporal cortex, a region linked to object perception and concept processing, were stronger to food words than to comparison word categories. These patterns of results demonstrate a correspondence between sensorimotor semantic properties of words - as revealed by empirical results obtained from semantic ratings-and the local patterns of cortical and cerebellar activity in the human brain elicited by these words.

\section{Semantics and the Motor System}

A range of previous studies have demonstrated a link between action verbs and sentences and the motor system of the human brain (see Introduction; also for review, Kiefer \& Pulvermüller, in press; Pulvermüller \& Fadiga, 2010; Fischer \& Zwaan, 2008; Kemmerer \& GonzalezCastillo, 2008; Kiefer, Sim, Herrnberger, Grothe, \& Hoenig, 2008). In particular, they demonstrated that it is possible to map specific semantic features of verbs to sections of the premotor and motor cortex, as brain areas controlling body parts involved in carrying out the word-related actions became active to the words themselves. In these studies, aspects of word meaning were thus reflected in somatotopic motor activity. This finding of semantic somatotopy was a breakthrough in the study of categoryspecific semantic brain processes, because it became possible for the first time to predict-from motor localizer tasks - the brain loci of specific semantic activation to linguistic elements. Semantic somatotopy has at present been observed across several different imaging methods (EEG, MEG, and fMRI), and magnetic stimulation experiments have demonstrated a causal influence of the motor cortex on the processing of specific types of action verbs. We here extend the finding of semantic somatotopy to nouns, now documenting a similar body-part mapping for nouns referring to objects typically manipulated by the hand (tools) and objects that are subject to eating (foods), thus affording actions of the mouth and tongue.

It is of theoretical interest that body-part semantics are reflected both by way of direct linkage to actions - as in the case of action verbs that are used to speak about actionsand by way of affordances of reference objects, which indirectly "call for" specific actions. That objects of different types have affordances of different types, and therefore, "call for" different kinds of actions has been repeatedly emphasized in the psychological literature after Gibson had coined the general concept (Gibson, 1982; Gibson \& Rader, 1979; Gibson, 1977). In the neuroscience literature, object affordances are thought to be implemented in the brain by way of canonical sensorimotor circuits connecting motor and perceptual neurons. The numerous reports in which perception of an object evokes the motor activity necessary for acting upon it (Rizzolatti \& Craighero, 2004; Jeannerod, Arbib, Rizzolatti, \& Sakata, 1995; see Fischer \& Zwaan, 2008, for review) can be attributed to these circuits. Similar to the well-known mirror neuron circuits (Rizzolatti \& Arbib, 1998; Gallese, Fadiga, Fogassi, \& Rizzolatti, 1996), these sensorimotor object representations can become a basis of semantic processing when coupled to word forms by way of learning (Pulvermüller \& Fadiga, 2010; Pulvermüller, 1999). In the context of semantic somatotopy, it has recently been argued that the mere capacity to perform an action on an object is not reflected in specific brain activation patterns in sensorimotor systems, whereas if the object's function is defined with respect to given actions, the semantic links to these actions are reflected in sensorimotor brain activation (Rueschemeyer, van Rooij, Lindemann, Willems, \& Bekkering, 2010). This important point is confirmed by the present results. Note that words referring to food, which indeed can be manipulated by the hands, failed to activate the finger regions of cortex and, concordantly, also failed to elicit high ratings of arm-hand action relationship at the semantic level. In contrast, the much more characteristic, essential, and actually defining feature of foods - to be "manipulated" by the mouthwas reflected not only in semantic ratings but also in the activation of motor cortex next to the tongue representation defined by overt motor activity. In parallel, the semantically critical object affordance of tools - to be manipulated by the hands-was reflected in semantic ratings on tool words and in motor cortex activation next to the area most strongly sparked by finger movements.

That noun-related object affordances show similar motor somatotopy as action verbs can be confirmed by mapping the cortical activation loci of previous studies on face-, arm-, and leg-related verbs together with those found for the nouns examined here. Figure 5 shows such a map, which we compile here following Kemmerer and Gonzalez-Castillo (2008). Note the close vicinity of nounand verb-elicited activation peaks, which argues against a general noun-verb difference in cortical mapping. Note, furthermore, that dissociations along the semantic dimension of body-part relatedness are consistently mapped, with few exceptions, and similarly for verbs and noun categories examined in the present work. It may therefore be that previously reported noun-verb differences in brain activation were a consequence of differences in semantic features between nouns and verbs and possibly also between subclasses of members of these large lexical categories, such as abstract and concrete items (for further discussion, see Vigliocco, Vinson, Druks, Barber, \& Cappa, 2011; Barber, Kousta, Otten, \& Vigliocco, 2010; Crepaldi, Berlingeri, Paulesu, \& Luzzatti, 2010; Pulvermüller et al., 1999). Figure 5 also shows a degree of consistency of motor somatotopy over several studies from different labs. Note, however, that a small number of foci do not conform to the overall pattern and act as outliers. In addition, we note that not all studies could replicate semantic somatotopy for word meaning (de Zubicaray, Postle, McMahon, Meredith, \& Ashton, 2010; Postle, McMahon, Ashton, Meredith, \& de Zubicaray, 2008) and action meaning (Galati et al., 2008), possibly due to methodological issues such as the use of blocked instead of event-related designs and possibly to the influence of task and context (Table 5). 
Figure 5. Summary of results on frontocentral activations elicited by words with a semantic relationship to actions. Different studies are indexed with specific symbols (see legend). Foci of significant activation to words, phrases, or sentences semantically related to actions involving the mouth or face are shown in green, those activated by hand-arm-related language in red, and those sparked by foot-leg-related language in blue. The topography of these activation foci seen across studies reflects the cortical representation of body parts semantically related to the stimulus words, including both verbs and nouns. Please note the somatotopic mapping pattern in the central sulcus and anterior to it (dorsal blue, lateral red, inferior green, with few exceptions) but the lack of consistent somatotopy posterior to the central sulcus.

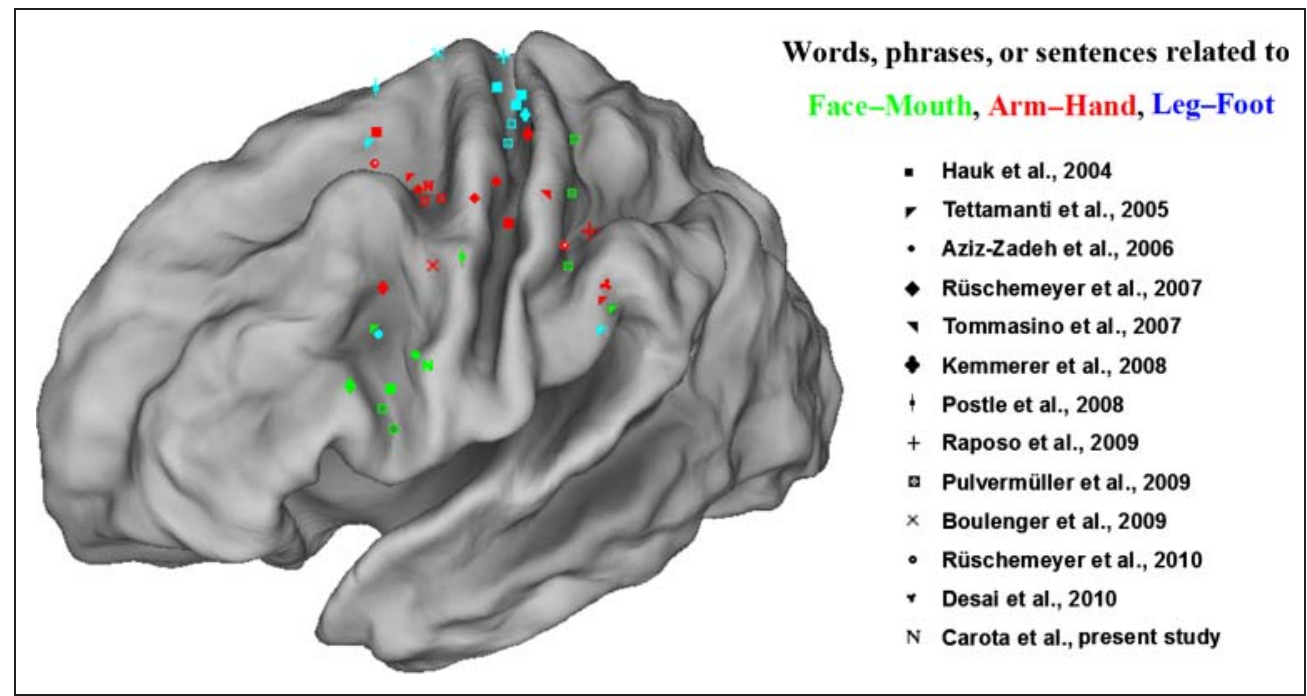

Along with previous studies on category-specific semantic activations in the human brain, these results may offer a first explanation as to why neuroimaging studies report such a diverse array of areas active in semantic processing. Essentially, semantic processing has been reported in all parts of the left language-dominant hemisphere of right-handed study participants (for review, see Binder, Desai, Graves, \& Conant, 2009; Vigneau et al., 2006; Pulvermüller, 1999). The more fine-grained approach to semantic categories put forward here might explain at least some of this local variability in terms of the semantic type of stimulus word under study (Pulvermüller, Kherif, Hauk, Mohr, \& Nimmo-Smith, 2009).

\section{Inferior Temporal and Cerebellar Activation}

A range of neuroimaging studies on semantic category processing revealed differential activation to animals and tools (for an overview, see Introduction; Martin, 2007). Most of these studies used pictures, sometimes in addition to a linguistic task, so that it is difficult to determine whether words, visual object display, or both contributed to category specific activity (see Introduction above). Studies focusing on animal-tool contrasts in picture naming reported differential activation of dorsolateral precentral cortex along with temporal areas, including the left middle temporal gyrus, fusiform, the anterior inferior temporal, and the occipital cortex along with the right ventrotemporal cortex (Martin \& Weisberg, 2003; Chao et al., 1999, 2002; Perani et al., 1999; Damasio, Grabowski, Tranel, Hichwa, \& Damasio, 1996; Martin et al., 1996). A most robust finding has been the category-specific activation of fusiform gyrus and adjacent areas at the bottom of the temporal cortex (Chouinard \& Goodale, 2010); however, this activity was sometimes seen to extend into the cerebellum (see, e.g., Figure 3 in Chao et al., 2002). Some uncertainty is possible as to the precise origin of such activity, given the wellknown spatial error due to spatial smoothing and normalization usually applied in functional neuroimaging (see, e.g., Friston et al., 1995). Our present results strongly suggest that the relatively strong activity to tool words does in fact originate in the right cerebellum (center coordinates $38-50-30,8-54-6,24-62-24)$, with overspill to the inferior temporal cortex. Screening of individual activation maps confirmed that in most participants, right posterior activation foci were indeed in the cerebellum (see Figure 6). Further arguments for this conclusion are threefold. First, the activation of the cerebellum in the processing of tool words is made plausible by the concurrent activation of dorsolateral motor and premotor cortex, because of the well-known fact that cortical motor systems interact with the cerebellum in movement coordination (Braitenberg, Heck, \& Sultan, 1997). Second, all three right cerebellar regions activated by tool words are close to the right cerebellar activation seen during right index finger movements $(24-52-24)$. Third, and most importantly, a further argument emerges from functional correlations. When correlating activity obtained for each of the three word categories in the three right cerebellar ROIs with that obtained in seven data-driven left central and precentral ROIs (center coordinates, see Tables 2 and 3; 189 comparisons), the only correlation surviving the Bonferroni-corrected 
Table 5.5

Table 5. Summary of Studies Reporting Frontoparietal Activations Elicited by Action Words as Depicted in Figure 5

\begin{tabular}{|c|c|c|c|c|c|}
\hline Authors ${ }^{a}$ & Stimuli ${ }^{b}$ & Task & Mouth & Arm & $\operatorname{Leg}$ \\
\hline Hauk et al., 2004 & Face, arm, $\mathrm{leg}^{\mathrm{c}}$ action verbs & Silent reading & -501020 & $\begin{array}{l}-22264 \\
-38-2048\end{array}$ & $\begin{array}{r}-8-2664 \\
-22-3064 \\
-22-3462\end{array}$ \\
\hline Tettamanti et al., 2005 & $\begin{array}{l}\text { Spoken face, arm, leg } \\
\text { action-related sentences }\end{array}$ & Listening & $\begin{array}{l}-44224 \\
-60-3432\end{array}$ & $\begin{array}{l}-30-256 \\
-62-2636\end{array}$ & $\begin{array}{l}-26464 \\
-64-3228\end{array}$ \\
\hline $\begin{array}{l}\text { Aziz-Zadeh, Wilson, Rizzolatti, \& } \\
\text { Iacoboni, } 2006\end{array}$ & Face, arm, leg action phrases & Silent reading & -54426 & $-30-646$ & -40628 \\
\hline Rüschemeyer, Brass, \& Friederici, 2007 & Arm action verbs & Silent reading and lexical decision & NA & $\begin{array}{l}-47-957 \\
-44-1559\end{array}$ & NA \\
\hline Tomasino, Werner, Weiss, \& Fink, 2007 & Arm, action (vs. nonaction) phrases & Action imagery & NA & $-50-2456$ & NA \\
\hline $\begin{array}{l}\text { Kemmerer, Gonzalez-Castillo, Talavage, } \\
\text { Patterson, \& Wiley, } 2008\end{array}$ & Face, arm, leg action verbs, & Semantic similarity judgment & -501820 & $\begin{array}{l}-461040 \\
-28-3062\end{array}$ & $-28-3260$ \\
\hline Postle et al., 2008 & Face, arm, leg action verbs & Silent reading & $-51-651^{\mathrm{d}}$ & & $-9-956^{\mathrm{e}}$ \\
\hline Pulvermüller et al., 2009, exp 1 & Face, arm, leg action verbs & Silent reading & $\begin{array}{l}-491116 \\
-32-3858 \\
-44-2940\end{array}$ & $-32-552$ & $-19-2961$ \\
\hline Pulvermüller et al., 2009, exp 2 & Face, arm, leg action verbs & Silent reading & $\begin{array}{l}-50910 \\
-38-3451\end{array}$ & $-34-1050$ & $-20-2657$ \\
\hline Boulenger, Hauk, \& Pulvermüller, 2009 & $\begin{array}{l}\text { Idiomatic/literal sentences with } \\
\text { arm/leg verbs }\end{array}$ & Silent reading & $\mathrm{NA}$ & -54444 & $-5-1875$ \\
\hline Raposo, Moss, Stamatakis, \& Tyler, 2009 & Arm and leg action verbs & Listening & NA & $-44-1456$ & $-6-2668$ \\
\hline Desai, Binder, Conant, \& Seidenberg, 2010 & Hand-arm action sentences & Listening & NA & $-55-3437$ & NA \\
\hline Rueschemeyer et al., 2010 & $\begin{array}{l}\text { Functionally (vs. volumetrically) } \\
\text { manipulable object nouns }\end{array}$ & $\begin{array}{l}\text { lexical decision (no-go } \\
\text { response to words) }\end{array}$ & NA & $\begin{array}{l}-15252 \\
-34-3636\end{array}$ & NA \\
\hline Carota et al., present study & Food and animal nouns & Silent reading & -60628 & $-30-852$ & NA \\
\hline
\end{tabular}

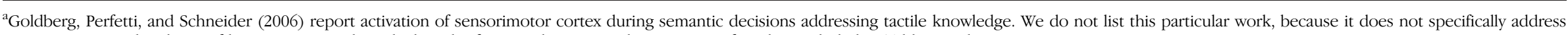
semantic action-relatedness of linguistic materials-which is the focus and common denominator of studies included in Table 5 and Figure 5.

${ }^{\mathrm{b}}$ Unless otherwise mentioned, written stimuli were used.

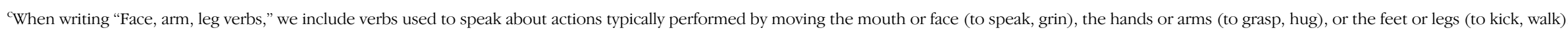

${ }^{\mathrm{d}}$ This, compared with other studies, far too dorsal tongue ROI showed significantly stronger activation to "mouth" words than to "hand" words, $t(1,16)=2.22, p<.05$.

'This foot ROI showed numerically (but reportedly not significantly) enhanced hemodynamic responses to "foot" words compared with "face" and "hand" words. 

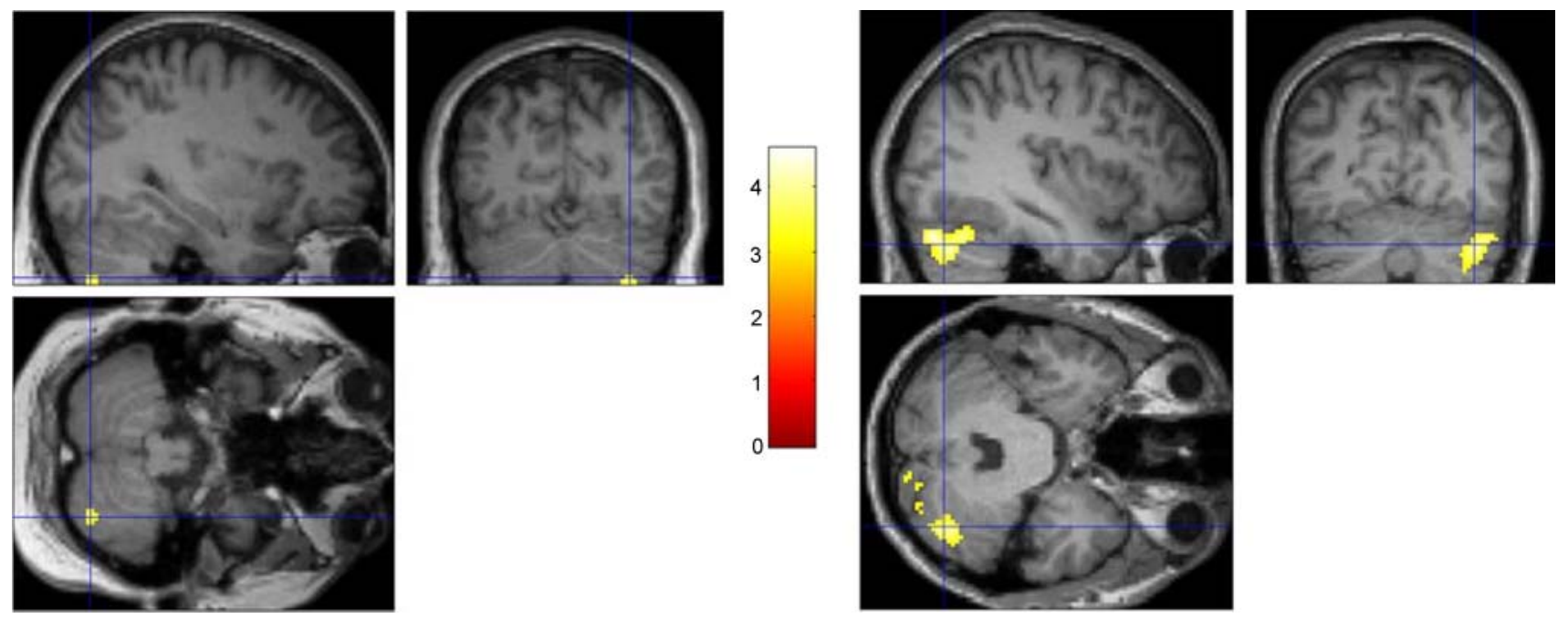

Figure 6. To ascertain the true location of right inferior posterior activation to tool nouns (vs. baseline), individual participants' brains were overlaid with their activation maps $(p<.001$, uncorrected). The figure shows activations in two representative participants. Note that activation was seen in the cerebellum, but not in inferior temporal or fusiform gyrus.

significance level (0.00065) was between the left precentral and postcentral cortex (center coordinate at $-58-1222)$ and right cerebellum $(8-54-6)$, wherein tool words elicited local activation maxima $[t(18)=5.73$, $\left.r=0.82, r^{2}=0.67, p<.000031\right]$. This is clear evidence that the category-specific activation enhancement to tool words in the left sensorimotor and right cerebellar loci originates from the well-known motor loop linking together the cortical motor systems and the cerebellum (Braitenberg et al., 1997). However, we cannot exclude that the right fusiform cortex might also play a role. In the present context, the strong involvement of hand motor cortical systems and the cerebellum can be related to the semantic properties of tool words objectified by semantic ratings, which showed not only enhanced hand action relatedness but, in addition, stronger general action relatedness compared with the other noun categories included in this study. In contrast, the relatively stronger activation of the left fusiform and posterior temporal areas to food words (most obvious from ROIs around $-38-34-20$ and $-46-60-10$ ) replicates, in part, earlier findings and might be related to specific visual properties of typical reference objects of these words (Chouinard \& Goodale, 2010; Martin, 2007). We did not see category effects in the left middle temporal cortex activations previously reported, specifically during naming of tools (Chouinard \& Goodale, 2010; Martin, 2007). In our present study, middle temporal cortex was active to the same degree to all word categories tested (Tables 2 and 3). Furthermore, we could not confirm the expected dissociation between animal and tool words in the left fusiform gyrus, wherein, instead, food words turned out to exhibit stronger hemodynamic responses than the other two experimental conditions (Figure 4A).

\section{Food, Valence, Odor-Taste, and OFC}

Alongside the category-specific activations in the motor system, the cerebellum, and the inferior temporal cortex, the OFC (BA 47, -34 $30-16$ ) showed comparatively large activation to food words. Previous work demonstrated a cognitive-anatomical association between emotion processing and the OFC. More specifically, the OFC was found to be sensitive to valence, the positive or negative affectiveemotional dimension, but not arousal, the generally activating emotional feature, which instead was manifest in amygdala activity (Anderson et al., 2003). Such valence specificity was found for odor stimuli and replicated for emotion words (Lewis, Critchley, Rotshtein, \& Dolan, 2007). That words semantically related to odors can also elicit orbito-frontal activity was shown in separate work (González et al., 2006), although in this case, it was not clear whether odor relatedness or emotional-affective variables were critical for the effect. Most recently, a link between taste-related meaning of words (such as "salt") and OFC activation has also been reported (Barrós-Loscertales et al., in press). On this background, the suggestion arises that the comparatively strong orbito-frontal activity evoked by our food word stimuli might be indexed specifically by the high values of the affective-emotional dimension of valence characterizing this category, possibly in conjunction with odor and taste connotations. Note that our food words were indeed characterized by comparatively high emotionalaffective valence ratings. However, we hasten to add that the field is still to a degree split with regard to the brain correlates of affective-emotional meaning. For example, one study found brain correlates of valence in the cingulate gyrus, the lingual gyrus, and the hippocampus (Kuchinke et al., 2005), whereas, contrary to the reports by Lewis et al. (2007), orbito-frontal activity seemed to index the degree 
of semantic arousal the words elicited. More research is necessary to elucidate the brain basis of affective-emotional meaning, especially as broad cover terms such as "arousal" and "valence" may not be easily related to a unique corresponding mechanism. Furthermore, the semantic links between words and odor and taste knowledge deserves future investigation.

\section{Conclusions}

In this study of category-specific brain activation during passive reading of nouns, it emerged that dorsal as well as ventral streams of the cortex reflect the meaning of stimulus words. The affordances of the objects to which nouns refer were reflected in the motor system, such that food words specifically activated tongue motor cortex and tool words activated finger motor cortex. Food words also strongly activated the left OFC, possibly related to the positive affective-emotional valence of foods, along with the left fusiform cortex. Surprisingly, activation to tool words stood out in the right cerebellum, possibly because of concordant cortical-cerebellar motor loops invoked by the massive semantic action links of these words. Taken together, our findings are consistent with a distributed action-perception model of semantic representation (Pulvermüller \& Fadiga, 2010; Pulvermüller, 2001), in which semantic features are linked together by means of functional webs of neurons that strengthen their connections according to Hebbian learning principles (Tsumoto, 1992; Hebb, 1949). According to this model, neuronal circuits located in the perisylvian areas store word form and their combinatorial properties; referential semantics and semantic relationships between words and their typical action and interaction contexts is, however, laid down in semantic circuits distributed throughout the cortex, reaching into sensory and motor systems. In this sense, category-specific semantic activation in sensorimotor systems of the brain can be understood, at least in part, as an index of word meaning.

\section{Acknowledgments}

We thank Alex Martin for his insightful input and two anonymous reviewers for their helpful comments at different stages of this work.

Reprint requests should be sent to Francesca Carota or Friedemann Pulvermüller, Medical Research Council Cognition and Brain Sciences Unit, 15 Chaucer Road, Cambridge CB2 2EF, United Kingdom, or via e-mail: Francesca.Carota@mrc-cbu.cam.ac.uk, Friedemann.Pulvermuller@fu-berlin.de.

\section{REFERENCES}

Anderson, A. K., Christoff, K., Stappen, I., Panitz, D., Ghahremani, D. G., Glover, G., et al. (2003). Dissociated neural representations of intensity and valence in human olfaction. Nature Neuroscience, 6, 196-202.

Aziz-Zadeh, L., Wilson, S. M., Rizzolatti, G., \& Iacoboni, M. (2006). Congruent embodied representations for visually presented actions and linguistic phrases describing actions. Current Biology, 16, 1818-1823.

Baayen, H., Piepenbrock, R., \& van Rijn, H. (1993). The CELEX lexical database (CD-ROM). Pennsylvania, PA: Linguistic Data Consortium.

Barber, H. A., Kousta, S. T., Otten, L. J., \& Vigliocco, G. (2010). Event-related potentials to event-related words: Grammatical class and semantic attributes in the representation of knowledge. Brain Research, 1332, 65-74.

Barrós-Loscertales, A., González, J., Pulvermüller, F., VenturaCampos, N., Bustamante, J. C., Costumero, V., et al. (in press). Reading "salt" activates gustatory brain regions: fMRI evidence for semantic grounding in a novel sensory modality. Cerebral Cortex.

Barsalou, L. W. (1999). Perceptual symbol systems. Behavioural and Brain Sciences, 22, 577-609; discussion 610-560.

Barsalou, L. W. (2008). Grounded cognition. Annual Review of Psychology, 59, 617-645.

Binder, J. R., Desai, R. H., Graves, W. W., \& Conant, L. L. (2009). Where is the semantic system? A critical review and meta-analysis of 120 functional neuroimaging studies. Cerebral Cortex, 19, 2767-2796.

Boulenger, V., Hauk, O., \& Pulvermüller, F. (2009). Grasping ideas with the motor system: Semantic somatotopy in idiom comprehension. Cerebral Cortex, 19, 1905-1914.

Braitenberg, V., Heck, D., \& Sultan, F. (1997). The detection and generation of sequences as a key to cerebellar function: Experiments and theory. Behavioral and Brain Sciences, 20, 229-245.

Buccino, G., Binkofski, F., Fink, G. R., Fadiga, L., Fogassi, L., Gallese, V., et al. (2001). Action observation activates premotor and parietal areas in a somatotopic manner: An fMRI study. European Journal of Neuroscience, 13, 400-404.

Cattell, R. B., \& Cattell, A. K. S. (1960). Handbook for the individual or group Culture Fair Intelligence Test. Champaign, IL: Testing Inc.

Chao, L. L., Haxby, J. V., \& Martin, A. (1999). Attribute-based neural substrates in temporal cortex for perceiving and knowing about objects. Nature Neuroscience, 2, 913-919.

Chao, L. L., Weisberg, J., \& Martin, A. (2002). Experiencedependent modulation of category-related cortical activity. Cerebral Cortex, 12, 545-551.

Chouinard, P. A., \& Goodale, M. A. (2010). Category-specific neural processing for naming pictures of animals and naming pictures of tools: An ALE meta-analysis. Neuropsychologia, 48, 409-418.

Chumbley, J., \& Friston, K. J. (2009). False discovery rate revisited: FDR and topological inference using Gaussian random fields. Neuroimage, 44, 62-70.

Chumbley, J., Worsley, K. J., Flandin, G., \& Friston, K. J. (2010). Topological FDR for neuroimaging. Neuroimage, 49, 3057-3064.

Crepaldi, D., Berlingeri, M., Paulesu, E., \& Luzzatti, C. (2010). A place for nouns and a place for verbs? A critical review of neurocognitive data on grammatical-class effects. Brain and Language, 116, 33-49.

Damasio, H., Grabowski, T. J., Tranel, D., Hichwa, R. D., \& Damasio, A. R. (1996). A neural basis for lexical retrieval. Nature, 380, 499-505.

D’Ausilio, A., Pulvermüller, F., Salmas, P., Bufalari, I., Begliomini, C., \& Fadiga, L. (2009). The motor somatotopy of speech perception. Current Biology, 19, 381-385.

de Saussure, F. (1916). Cours de linguistique generale. Paris: Payot.

de Zubicaray, G., Postle, N., McMahon, K., Meredith, M., \& Ashton, R. (2010). Mirror neurons, the representation of word meaning, and the foot of the third left frontal convolution. Brain and Language, 112, 77-84. 
Desai, R. H., Binder, J. R., Conant, L. L., \& Seidenberg, M. S. (2010). Activation of sensory-motor areas in sentence comprehension. Cerebral Cortex, 20, 468-478.

Fadiga, L., Craighero, L., Buccino, G., \& Rizzolatti, G. (2002). Speech listening specifically modulates the excitability of tongue muscles: A TMS study. European Journal of Neuroscience, 15, 399-402.

Fazio, P., Cantagallo, A., Craighero, L., D’Ausilio, A., Roy, A., Pozzo, T., et al. (2009). Encoding of human action in Broca's area. Brain, 132, 1980-1988.

Fischer, M. H., \& Zwaan, R. A. (2008). Embodied language: A review of the role of the motor system in language comprehension. Quarterly Journal of Experimental Psychology (Colchester), 61, 825-850.

Frege, G. (1980). Über Sinn und Bedeutung [first published in 1892]. In G. Patzig (Ed.), Funktion, Begriff, Bedeutung (pp. 25-50). Göttingen, Germany: Huber.

Friston, K. J. (1997). Testing for anatomically specified regional effects. Human Brain Mapping, 5, 133-136.

Friston, K. J., Ashburner, J., Frith, C. D., Poline, J.-B., Heather, J. D., \& Frackowiak, R. S. J. (1995). Spatial registration and normalization of images. Human Brain Mapping, 2, 165-189.

Friston, K. J., Fletcher, P., Josephs, O., Holmes, A., Rugg, M. D., \& Turner, R. (1998). Event-related fMRI: Characterizing differential responses. Neuroimage, 7, 30-40.

Galati, G., Committeri, G., Spitoni, G., Aprile, T., Di Russo, F., Pitzalis, S., et al. (2008). A selective representation of the meaning of actions in the auditory mirror system. Neuroimage, 40, 1274-1286.

Gallese, V., Fadiga, L., Fogassi, L., \& Rizzolatti, G. (1996). Action recognition in the premotor cortex. Brain, 119, 593-609.

Gibson, J. J. (1977). The theory of affordances. In R. Shaw \& J. Bransford (Eds.), Perceiving, acting and knowing: Toward an ecological psychology (pp. 67-82). Hillsdale, NJ: Erlbaum.

Gibson, E., \& Rader, N. (1979). Attention, the perceiver as performer. In G. Hale \& M. Lewis (Eds.), Attention and cognitive development (pp. 1-12). New York: Plenum Press.

Gibson, E. J. (1982). The concept of afforance in development: The renascence of functionalism. In W. A. Collins (Ed.), The concept of development (Vol. 15, pp. 55-81). Hillsdale, NJ: Erlbaum.

Gleitman, L. R. (1994). Words, words, words. Philosophical Transactions of the Royal Society of London, Series B, Biological Sciences, 346, 71-77.

Goldberg, R. F., Perfetti, C. A., \& Schneider, W. (2006). Perceptual knowledge activates sensory brain regions. The Journal of Neuroscience, 26, 4917-4921.

González, J., Barros-Loscertales, A., Pulvermüller, F., Meseguer, V., Sanjuán, A., Belloch, V., et al. (2006). Reading cinnamon activates olfactory brain regions. Neuroimage, 32, 906-912.

Grafton, S. T., Fadiga, L., Arbib, M. A., \& Rizzolatti, G. (1997). Premotor cortex activation during observation and naming of familiar tools. Neuroimage, 6, 231-236.

Greenfield, P. M. (1991). Language, tools and brain: The ontogeny and phylogeny of hierarchically organized sequential behavior. Behavioral and Brain Sciences, 14, 531-595.

Grezes, J., Armony, J. L., Rowe, J., \& Passingham, R. E. (2003). Activations related to "mirror" and "canonical" neurones in the human brain: An fMRI study. Neuroimage, 18 , 928-937.

Grezes, J., \& Decety, J. (2002). Does visual perception of object afford action? Evidence from a neuroimaging study. Neuropsychologia, 40, 212-222.

Hari, R., Forss, N., Avikainen, S., Kirveskari, E., Salenius, S., \& Rizzolatti, G. (1998). Activation of human primary motor cortex during action observation: A neuromagnetic study. Proceedings of the National Academy of Sciences, U.S.A., 95 15061-15065.

Hauk, O., Johnsrude, I., \& Pulvermüller, F. (2004). Somatotopic representation of action words in the motor and premotor cortex. Neuron, 41, 301-307.

Hebb, D. O. (1949). The organization of behavior. A neuropsychological theory. New York: Wiley.

Jeannerod, M., Arbib, M. A., Rizzolatti, G., \& Sakata, H. (1995). Grasping objects: The cortical mechanisms of visuomotor transformation. Trends in Neurosciences, 18, 314-320.

Kemmerer, D., \& Gonzalez-Castillo, J. (2008). The two-level theory of verb meaning: An approach to integrating the semantics of action with the mirror neuron system. Brain and Languages, 112, 54-76.

Kemmerer, D., Gonzalez-Castillo, J., Talavage, T., Patterson, S., \& Wiley, C. (2008). Neuroanatomical distribution of five semantic components of verbs: Evidence from fMRI. Brain and Language, 107, 16-43.

Kiefer, M., \& Pulvermüller, F. (in press). Conceptual representations in mind and brain: Theoretical developments, current evidence and future directions. Cortex.

Kiefer, M., Sim, E. J., Herrnberger, B., Grothe, J., \& Hoenig, K. (2008). The sound of concepts: Four markers for a link between auditory and conceptual brain systems. Journal of Neuroscience, 28, 12224-12230.

Kuchinke, L., Jacobs, A. M., Grubich, C., Vo, M. L., Conrad, M., \& Herrmann, M. (2005). Incidental effects of emotional valence in single word processing: An fMRI study. Neuroimage, 28, 1022-1032.

Landau, B., \& Gleitman, L. R. (1985). Language and experience. Evidence from the blind child. Cambridge, MA: Harvard University Press.

Lewis, P. A., Critchley, H. D., Rotshtein, P., \& Dolan, R. J. (2007). Neural correlates of processing valence and arousal in affective words. Cerebral Cortex, 17, 742-748.

Lyons, J. (1977). Semantics (Vols. 1 and 2). Cambridge: Cambridge University Press.

Maes, F., Collignon, A., Vandermeulen, D., Marchal, G., \& Suetens, P. (1997). Multimodality image registration by maximization of mutual information. IEEE Transactions on Medical Imaging, 16, 187-198.

Mahon, B. Z., Anzellotti, S., Schwarzbach, J., Zampini, M., \& Caramazza, A. (2009). Category-specific organization in the human brain does not require visual experience. Neuron, 63 , $397-405$

Martin, A. (2007). The representation of object concepts in the brain. Annual Review of Psychology, 58, 25-45.

Martin, A., \& Weisberg, J. (2003). Neural foundations for understanding social and mechanical concepts. Cognitive Neuropsychology, 20, 575-587.

Martin, A., Wiggs, C. L., Ungerleider, L. G., \& Haxby, J. V. (1996). Neural correlates of category-specific knowledge. Nature, 379, 649-652

Oldfield, R. C. (1971). The assessment and analysis of handedness: The Edinburgh Inventory. Neuropsychologia, 9, 97-113.

Perani, D., Schnur, T., Tettamanti, M., Gorno-Tempini, M., Cappa, S. F., \& Fazio, F. (1999). Word and picture matching: A PET study of semantic category effects. Neuropsychologia, 37, 293-306.

Postle, N., McMahon, K. L., Ashton, R., Meredith, M., \& de Zubicaray, G. I. (2008). Action word meaning representations in cytoarchitectonically defined primary and premotor cortices. Neuroimage, 43, 634-644.

Pulvermüller, F. (1999). Words in the brain's language. Behavioral and Brain Sciences, 22, 253-336. 
Pulvermüller, F. (2001). Brain reflections of words and their meaning. Trends in Cognitive Sciences, 5, 517-524.

Pulvermüller, F. (2005). Brain mechanisms linking language and action. Nature Reviews Neuroscience, 6, 576-582.

Pulvermüller, F., \& Fadiga, L. (2010). Active perception: Sensorimotor circuits as a cortical basis for language. Nature Reviews Neuroscience, 11, 351-360.

Pulvermüller, F., Huss, M., Kherif, F., Moscoso del Prado Martin, F., Hauk, O., \& Shtyrov, Y. (2006). Motor cortex maps articulatory features of speech sounds. Proceedings of the National Academy of Sciences, U.S.A. 103, 7865-7870.

Pulvermüller, F., Kherif, F., Hauk, O., Mohr, B., \& Nimmo-Smith, I. (2009). Cortical cell assemblies for general lexical and categoryspecific semantic processing as revealed by fMRI cluster analysis. Human Brain Mapping, 30, 3837-3850.

Pulvermüller, F., Lutzenberger, W., \& Preissl, H. (1999). Nouns and verbs in the intact brain: Evidence from event-related potentials and high-frequency cortical responses. Cerebral Cortex, 9, 498-508.

Pulvermüller, F., Shtyrov, Y., \& Ilmoniemi, R. J. (2003). Spatiotemporal patterns of neural language processing: An MEG study using Minimum-Norm Current Estimates. Neuroimage, 20, 1020-1025.

Raposo, A., Moss, H. E., Stamatakis, E. A., \& Tyler, L. K. (2009). Modulation of motor and premotor cortices by actions, action words and action sentences. Neuropsychologia, 47, 338-396.

Rizzolatti, G., \& Arbib, M. A. (1998). Language within our grasp. Trends in Neurosciences, 21, 188-194.

Rizzolatti, G., \& Craighero, L. (2004). The mirror-neuron system. Annual Review in Neuroscience, 27, 169-192.

Rizzolatti, G., Fadiga, L., Gallese, V., \& Fogassi, L. (1996). Premotor cortex and the recognition of motor actions. Cognitive Brain Research, 3, 131-141.

Rueschemeyer, S. A., van Rooij, D., Lindemann, O., Willems, R. M., \& Bekkering, H. (2010). The function of words: Distinct neura correlates for words denoting differently manipulable objects. Journal of Cognitive Neurosciences, 22, 1844-1851.

Rüschemeyer, S. A., Brass, M., \& Friederici, A. D. (2007). Comprehending prehending: Neural correlates of processing verbs with motor systems. Journal of Cognitive

Neurosciences, 19, 855-865.
Shapiro, K., \& Caramazza, A. (2003). The representation of grammatical categories in the brain. Trends in Cognitive Sciences, 7, 201-206.

Tettamanti, M., Buccino, G., Saccuman, M. C., Gallese, V., Danna, M., Scifo, P., et al. (2005). Listening to action-related sentences activates fronto-parietal motor circuits. Journal of Cognitive Neuroscience, 17, 273-281.

Tomasello, M. (2005). Constructing a language: A usage-based theory of language acquisition. Boston: Harvard University Press.

Tomasello, M., \& Kruger, A. C. (1992). Joint attention on actions: Acquiring verbs in ostensive and non-ostensive contexts. Journal of Child Language, 19, 311-333.

Tomasino, B., Werner, C. J., Weiss, P. H., \& Fink, G. R. (2007). Stimulus properties matter more than perspective: An fMRI study of mental imagery and silent reading of action phrases. Neuroimage, 36, T128-T141.

Tsumoto, T. (1992). Long-term potentiation and long-term depression in the neocortex. Progress in Neurobiology, 39, 209-228.

van Casteren, M., \& Davis, M. H. (2006). Mix, a program for pseudorandomization. Behavioural Research Methods, 38, 584-589.

van Casteren, M., \& Davis, M. H. (2007). Match: A program to assist in matching the conditions of factorial experiments. Behavioural Research Methods, 39, 973-978.

Vigliocco, G., Vinson, D. P., Druks, J., Barber, H., \& Cappa, S. F. (2011). Nouns and verbs in the brain: A review of behavioural, electrophysiological, neuropsychological and imaging studies. Neuroscience \& Bio-behavioural Review, 35, 407-426.

Vigneau, M., Beaucousin, V., Herve, P. Y., Duffau, H., Crivello, F., Houde, O., et al. (2006). Meta-analyzing left hemisphere language areas: Phonology, semantics, and sentence processing. Neuroimage, 30, 1414-1432.

Wittgenstein, L. (1953). Philosophical investigations. Oxford: Blackwell Publishers.

Worsley, K. J., Marrett, S., Neelin, P., Vandal, A. C., Friston, K. J., \& Evans, A. C. (1996). A unified statistical approach for determining significant signals in images of cerebral activation. Human Brain Mapping, 4, 58-73. 